\title{
Sports activity participation after curved periacetabular osteotomy for acetabular dysplasia
}

\author{
Yoshiki Takahashi ${ }^{1} \mathbb{D}$, Naonobu Takahira ${ }^{2,3^{*}}$ (D), Katsufumi Uchiyama ${ }^{4}$, Kensuke Fukushima ${ }^{4}$ (D), Mitsutoshi Moriya ${ }^{4}$,
} Manaka Shibuya ${ }^{1,5}$, Kouji Tsuda$^{1}$, Kiyoshi Tozaki ${ }^{1}$, Sho Kudo ${ }^{1}$, Hiroaki Kaneda ${ }^{1}$ D, Junya Sekita ${ }^{1}$ and Masashi Takaso ${ }^{4}$

\begin{abstract}
Background: Curved periacetabular osteotomy (CPO) was developed to treat acetabular dysplasia. Given that CPO can improve physical function in the early post-operative period, patients might be able to participate in sports activities post-operatively. Therefore, this study examined the post-operative sports activity participation and characteristics of acetabular dysplasia patients who have undergone CPO.

Methods: A total of 52 patients who underwent CPO for acetabular dysplasia were given a questionnaire on preand post-operative sports activities; 43 patients responded. We surveyed patients' sports activities, satisfaction, and physical function. Patients were divided according to whether they participated in sports activities after CPO. Physical function was compared before and after CPO.

Results: The pre- and post-operative sports activity participation rates were 55.8 and $72.1 \%$, respectively. Patients mostly performed low-impact sports activities. Moreover, patients who participated in sports activities postoperatively had smaller pre-operative range of motion of hip flexion and returned to full weight bearing earlier.

Conclusions: Among acetabular dysplasia patients who underwent CPO, 72.1\% participated in sports activities post-operatively. Post-operatively, patients participated not only in low-impact sports activities, but also in highimpact ones. These findings might be useful for advising patients who are concerned about participating in sports activities after CPO.
\end{abstract}

Keywords: Curved periacetabular osteotomy, Sports activity, Acetabular dysplasia, Physical function

\section{Background}

Acetabular dysplasia is the most common cause of secondary osteoarthritis (OA) [1]. Morphological features due to acetabular dysplasia result in instability and

\footnotetext{
*Correspondence: takahira@med.kitasato-u.ac.jp

${ }^{2}$ Department of Orthopaedic Surgery of Clinical Medicine, Rehabilitation Sciences and Functional Restoration, Science of Sensory and Motor Control, Graduate School of Medical Sciences, Kitasato University, 1-15-1 Kitasato, Minami-ku, Sagamihara-city, Kanagawa 252-0373, Japan

${ }^{3}$ Department of Rehabilitation, School of Allied Health Sciences, Kitasato University, 1-15-1 Kitasato, Minami-ku, Sagamihara-city, Kanagawa 252-0373, Japan

Full list of author information is available at the end of the article
}

abnormal loading on the articular cartilage [2, 3]; this can lead to degeneration of the articular cartilage, which in turn leads to OA. OA occurs in $15.7 \%$ of patients [4], causing pain and limiting range of motion, which can disturb participation in sports activities. Periacetabular osteotomy (PAO) is beneficial for young patients with acetabular dysplasia, with case series showing improvement in post-operative physical activity levels $[5,6]$ while preserving $60 \%$ of hips without requiring total hip arthroplasty at 20 years [7]. Moreover, van Bergayk et al. report that 47.6 and $95.2 \%$ of patients with acetabular dysplasia participated in sports activities before and after

(c) The Author(s). 2020 Open Access This article is licensed under a Creative Commons Attribution 4.0 International License, which permits use, sharing, adaptation, distribution and reproduction in any medium or format, as long as you give appropriate credit to the original author(s) and the source, provide a link to the Creative Commons licence, and indicate if changes were made. The images or other third party material in this article are included in the article's Creative Commons licence, unless indicated otherwise in a credit line to the material. If material is not included in the article's Creative Commons licence and your intended use is not permitted by statutory regulation or exceeds the permitted use, you will need to obtain permission directly from the copyright holder. To view a copy of this licence, visit http://creativecommons.org/licenses/by/4.0/ The Creative Commons Public Domain Dedication waiver (http://creativecommons.org/publicdomain/zero/1.0/) applies to the data made available in this article, unless otherwise stated in a credit line to the data. 
PAO, respectively [8]. However, another study reports a sports activity participation rate of $55.3 \%$ after $\mathrm{PAO}$ and a non-significant relationship with OA progression [9].

Meanwhile, curved periacetabular osteotomy (CPO), a modified PAO developed by Naito et al. [10], is indicated for patients with mild or severe dysplastic hips [11]. CPO provides pain relief and early improvement of hip abductor muscle strength because it preserves the hip abductor muscle, which reduces the dynamic instability of the hip joint during walking [12-14]. Another advantage of CPO is its low risk of necrosis of the femoral head and acetabulum owing to the maintenance of blood supply to the rotated acetabulum and the small skin incision required [10]. Thus, these benefits of CPO ultimately reduce post-operative complications, promote early rehabilitation, and increase the likelihood of being able to participate in sports activities. Nevertheless, there are few reports of post-operative daily life in patients who have undergone CPO. Thus, sports activity participation after $\mathrm{CPO}$ remains unknown. Given that $\mathrm{CPO}$ is a modified $\mathrm{PAO}$, we hypothesised that $\mathrm{CPO}$ increases participation in sports activities in patients with acetabular dysplasia to an extent equal to or greater than that of PAO. Therefore, this study evaluated the post-operative sports activity participation and characteristics of patients with acetabular dysplasia who underwent CPO.

\section{Methods}

\section{Study design and patients}

This retrospective, questionnaire-based study enrolled 59 consecutive patients with acetabular dysplasia who underwent $\mathrm{CPO}$ at our institution between January 1, 2013 and January 31, 2018. We pre-tested the sports activity questionnaire on members of our laboratory and then sent it to patients; 43 patients (82.7\%) responded (Fig. 1). Patients with severe cerebrovascular disease, cardiovascular disease, or mental health disorders that limited mobility were excluded.

This study was approved by the ethics committee of our institutions and was conducted in accordance with the Principles of the Declaration of Helsinki and the Good Clinical Practice guidelines. Information about informed consent to participate in the study was enclosed with the questionnaire. An opt-out form for informed consent was adopted.

\section{Questionnaire}

Fifty-two patients were mailed paper questionnaires comprising three sections (Additional file 1). The first section surveyed pre-operative participation in sports activities. Patients were asked whether they participated in sports activities as well as the types and frequency of sports activities. Sports activity participation was defined as exercise that the patient voluntarily performed, and impact was categorised as described by Klein et al. [15]. The second section surveyed patients' post-operative sports activity participation. Patients who participated in any sports activity were asked why they did so, whereas patients who did not were also asked this question and whether they hoped to participate in sports activities in the future. The third section collected information about patients' satisfaction with daily activities and sports activities as well as the Forgotten Joint Score (FJS) [16].

\section{Patient information}

Demographic characteristics during hospitalisation were obtained from medical records, including age at the time of surgery, sex, and body mass index (BMI). The

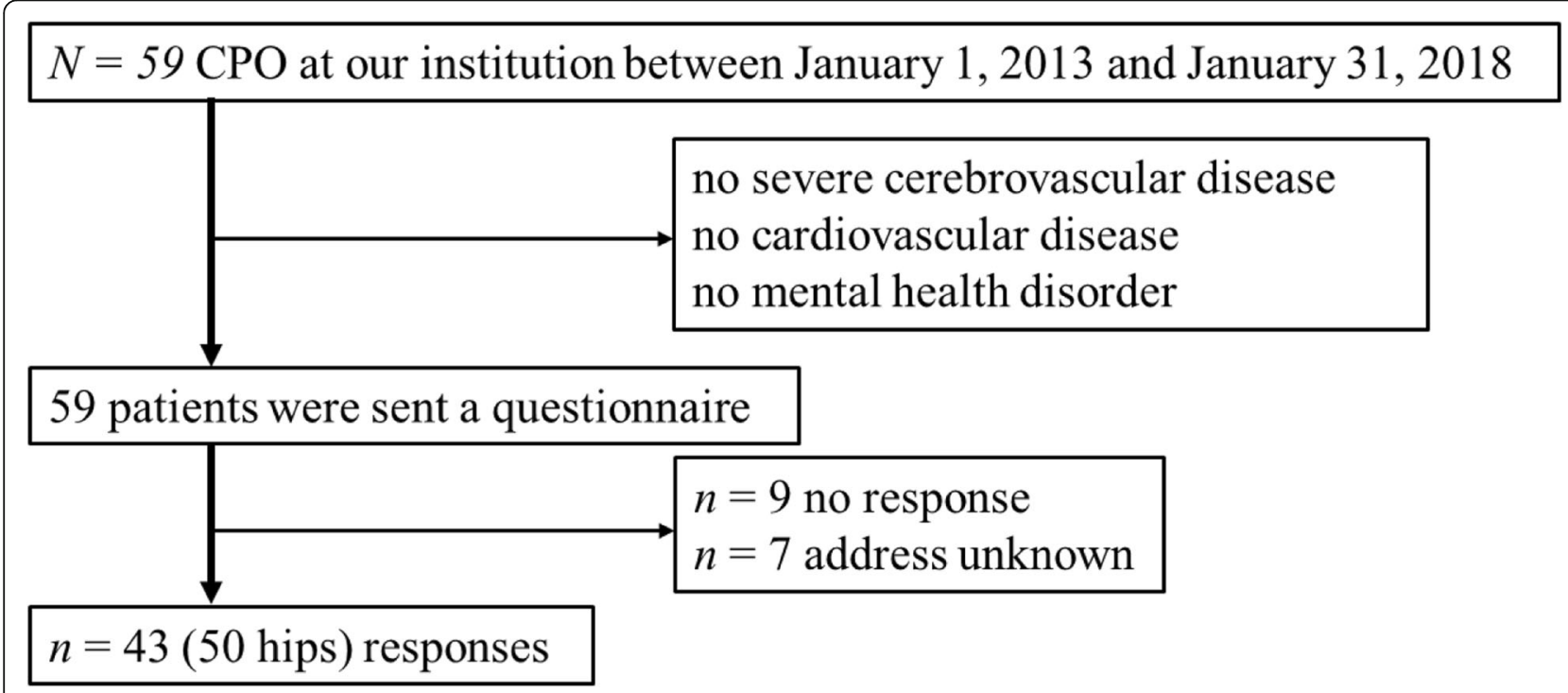

Fig. 1 Patient enrolment flowchart. CPO, curved periacetabular osteotomy 
following information was also obtained from medical records: time until straight leg-raising exercise possible; time until full weight bearing (FWB) was allowed; postoperative Japan Orthopaedic Association Hip Disease Evaluation Questionnaire (JHEQ) score [17]; and preoperative clinical characteristics upon admission, including hospitalisation, range of motion, lower-leg muscle strength, 10-m comfortable gait speed, 10-m maximum gait speed, and Harris Hip Score (HHS) [18]. The time until FWB was allowed and post-operative JHEQ scores were obtained at post-discharge follow-up. Range of motion, lower-leg muscle strength, 10-m comfortable gait speed, $10-\mathrm{m}$ maximum gait speed were assessed by physical therapists. The JHEQ comprises hip joint condition (visual analogue scale) and three subscales: pain, movement, and mental. Higher scores indicate higher quality of life.

\section{Statistical analysis}

The data were summarised using descriptive statistics. Pre- and post-operative sports activity participation rates were calculated by dividing the numbers of patients who participated in sports activities pre- or post-operatively by 43 (i.e. the number of patients who responded to the questionnaire). Patients were categorised into the 'participation group' or 'non-participation group' according to whether they participated in sports activities postoperatively. The Mann-Whitney $U$-test or KruskalWallis test was used, where appropriate, to compare demographic characteristics between groups. All statistical analyses were performed using $\mathrm{R}$ version 3.3.3 ( $\mathrm{R}$ Foundation). $P$-values less than 0.05 were considered statistically significant.

\section{Results}

\section{Questionnaire}

Patients responded to the questionnaire at a mean of $34.1 \pm 17.2$ months post-operatively (range: 8-69 months). The pre- and post-operative sports activity participation rates were $55.8 \%(n=24$ patients, 27 hips $)$ and $72.1 \%$ ( $n=31$ patients, 36 hips), respectively. The number of patients who participated in sports activities increased significantly from 24 pre-operatively to 31 postoperatively $(P<0.01)$. Of the 24 patients who participated in sports activities pre-operatively, 91.7\% $(n=22$ patients, 24 hips) participated in sports activities postoperatively. At the time of the survey, OA progressed in 1 case (with 46 months of follow-up), but there was no significant association with sports activity participation $(P=0.28)$; this patient did not participate in sports activities pre- or post-operatively. Patients performed many low-impact sports activities such as walking and swimming. Pre-operatively, 10 patients (12 cases) performed high-impact sports activities, such as volleyball and badminton, compared to 7 patients (7 cases) postoperatively (Fig. 2). Among the 7 patients who only participated in sports activities post-operatively, 4 patients participated in walking, 3 participated in training, 3 participated in yoga, 2 participated in road cycling, 2 participated in jogging, 1 participated in swimming, 1 participated in golf, 1 participated in bowling, and 1 participated in aerobics (including duplicate answers). Patients resumed sports activities at a mean of $12.7 \pm 10.8$ months post-operatively. The mean weekly frequencies of sport activities pre- and post-operatively were $2.7 \pm$ 1.7 and $2.7 \pm 2.2$ times, respectively. Patients' reasons for participating or not participating in sports activities are shown in Figs. 3 and 4, respectively.

\section{Physical function and satisfaction}

Physical function and satisfaction were compared between the participation and non-participation groups (Table 1). Compared to the non-participation group, the participation group had a significantly smaller range of motion of hip flexion pre-operatively and significantly earlier post-operative FWB allowed by clinician $(P=0.03$ and 0.02 , respectively). Moreover, 74.1 and $38.8 \%$ of patients reported being 'very satisfied' or 'slightly satisfied' with current life and sports activities, respectively (Table 2).

\section{Discussion}

We investigated acetabular dysplasia patients' participation in sports activities before and after $\mathrm{CPO}$, and compared patients who participated and did not participate in sports activities post-operatively. Patients who participated in sports activities post-operatively were allowed to return to FWB earlier than those who did not. To our knowledge, this is the first study on the sports activities of patients with acetabular dysplasia who have undergone CPO. Our results will help medical staff ascertain the likelihood that patients with acetabular dysplasia will be able to participate in sports activities after CPO.

In this study, the pre- and post-operative sports activity participation rates of acetabular dysplasia patients who underwent $\mathrm{CPO}$ were 55.8 and $72.1 \%$, respectively, versus 31.1 and $55.3 \%$ in patients who underwent $\mathrm{PAO}$, respectively [9]. Patients who underwent $\mathrm{CPO}$ had significantly higher pre- and post-operative sports activity participation rates than patients who underwent $\mathrm{PAO}$ $(P=0.047$ and $=0.003$, respectively). Although these results suggest that $\mathrm{CPO}$ might increase post-operative sports activity participation relative to $\mathrm{PAO}$, the preoperative participation rates were substantially different between studies. Therefore, future studies are required to compare sports activity participation rates after $\mathrm{CPO}$ and other osteotomies, such as rotational acetabular 


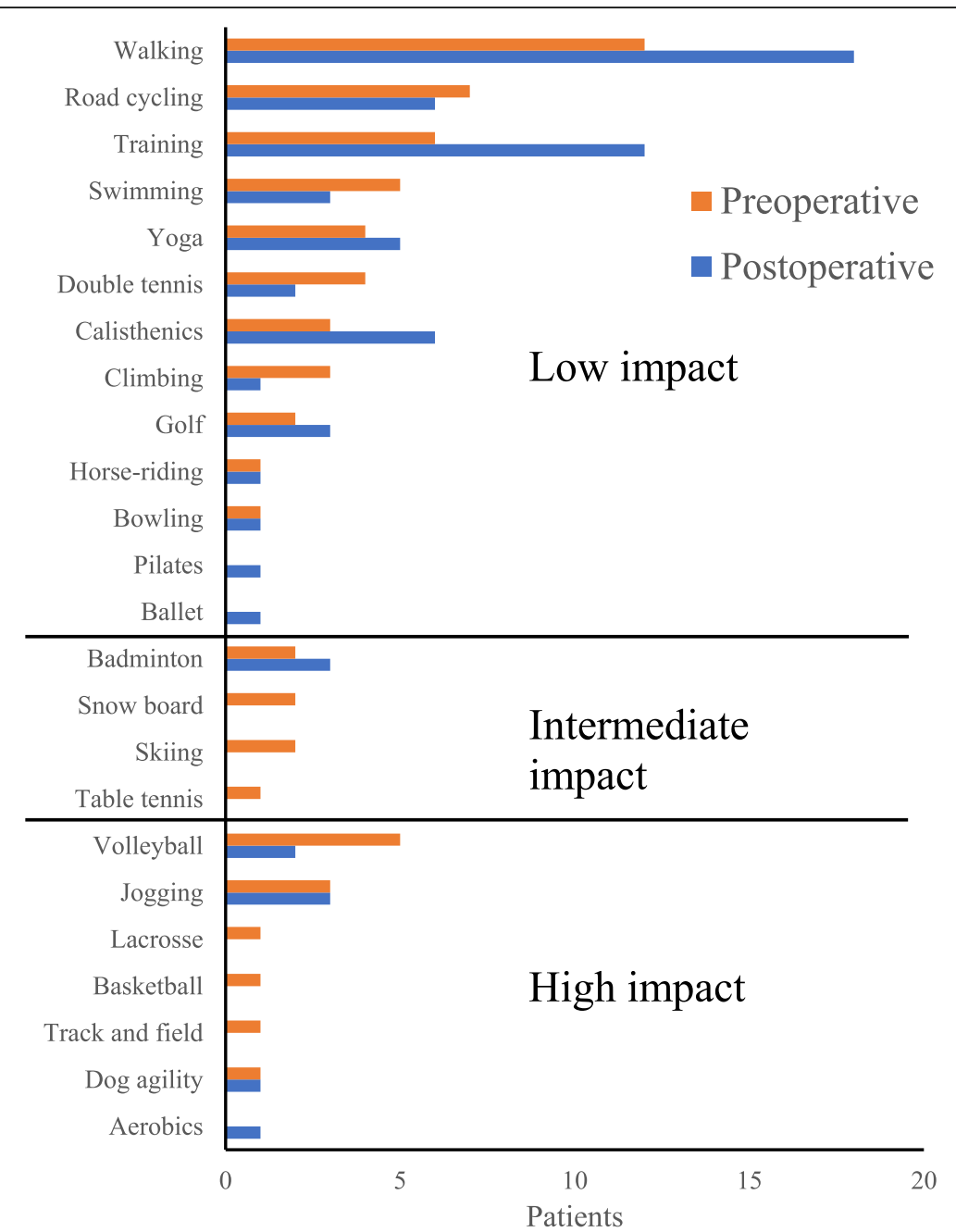

Fig. 2 Types and numbers of patients who participated in sports activities before and after curved periacetabular osteotomy (multiple responses allowed)

osteotomy and PAO, in patients with similar baseline sports activities participation.

Compared to PAO, CPO is less invasive and can create better contact between bone surfaces, resulting in stable fixation and tight bonding [10]. Because early postoperative rehabilitation is possible with CPO, early physical function can be improved. Thus, patients with improved physical function are more willing or able to maintain or improve physical function, resulting in higher sports activity participation. This is corroborated by patients' self-reported reasons for participating in sports activities (Fig. 2). Furthermore, activity level and satisfaction are reported to be correlated in patients with hip disease [19]. In this study, $74.1 \%$ of patients were satisfied with daily life, suggesting that high satisfaction might positively affect sports activity participation. Therefore, medical staff can use the results of this study to provide guidance to patients who want to participate in sports activities after CPO.
Patients participated in sports activities ranging from low to high impact, with the latter being performed less frequently; this trend is similar to previous reports on sports activities before and after total hip arthroplasty [20] or PAO [9]. Many low-impact sports activities are safe for patients to do alone and do not require higher physical functioning in comparison to high-impact sports activities. In addition, post-operative participation in sports activities is reported to be unrelated to OA progression regardless of sports activity impact [9]. Therefore, clinicians can recommend that patients who have undergone CPO participate in low-impact sports activities post-operatively. Meanwhile, a few patients in this study participated in high-impact sports activities. As such activities require high physical functioning, most patients likely refrained from participating in them owing to concerns of deterioration of physical condition, such as OA progression. However, Hara et al. report that among 162 acetabular dysplasia patients, participation in 


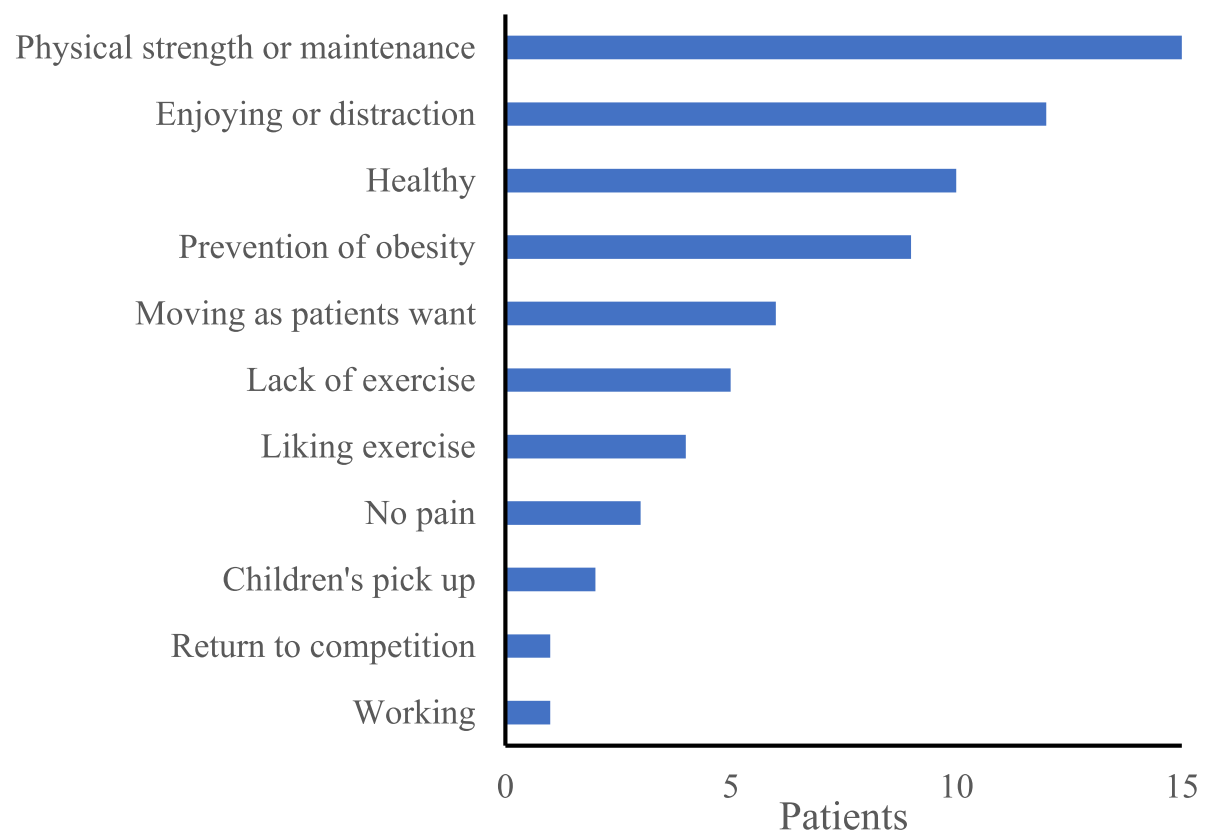

Fig. 3 Reasons for participating in sports activities after curved periacetabular osteotomy (multiple responses allowed)

high-impact sports activities after PAO did not significantly influence the progression of OA grade [9]. Because $\mathrm{CPO}$ is a modified PAO [10], it is expected to yield the same prognosis as PAO. Hence, some patients participate in high-impact sports activities after $\mathrm{CPO}$ or PAO. Therefore, clinicians should support patients who wish to participate in high-impact sports activities with careful follow-up, such as confirmation of OA grade.

The main reasons for not participating in sports activities post-operatively were lack of time and pain. The oldest patient in this study was 62 years. The retirement age in many workplaces in Japan is 65 years. Therefore, given that most patients in this study were younger, many might have had limited time for sports activities because of work. In addition, fear of pain or hip damage hinders post-operative participation in sports activities [21]. Therefore, clinicians should provide patients appropriate guidance for participating in sports activities after obtaining informed consent. Moreover, from the viewpoint of extending healthy life expectancy, it is preferable to advise low-impact sports activities such as walking and cycling. Accordingly, clinicians should avoid giving all patients uniform guidance regarding exercise and instead give individualised guidance, because patients who have undergone $\mathrm{CPO}$ might only be able to perform

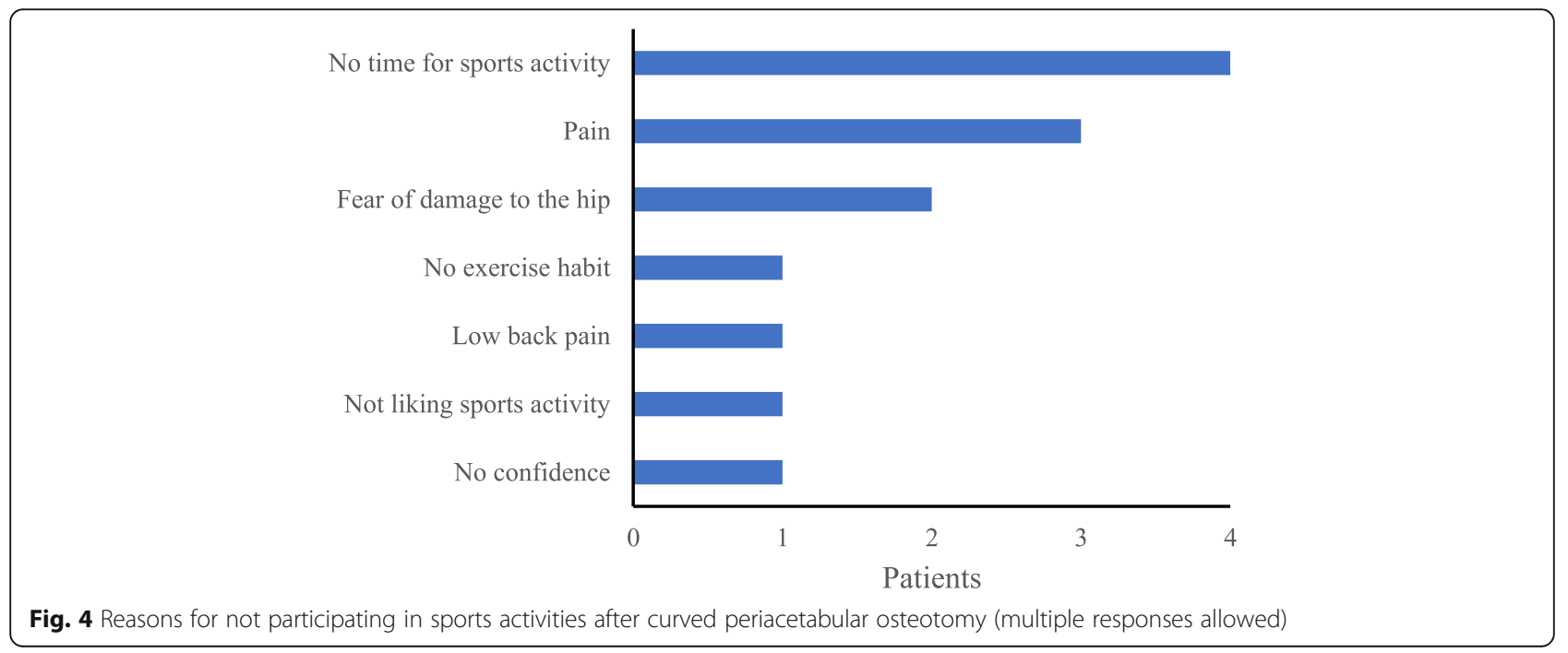


Table 1 Physical function and satisfaction in patients who participated or did not participate in sports activities post-operatively

\begin{tabular}{|c|c|c|c|}
\hline Factors & Participation group $(n=31)$ & Non-participation group $(n=12)$ & $P$-value \\
\hline Age (years) & $45.0(42.0-48.5)$ & $48.5(22.0-58.0)$ & .61 \\
\hline Body mass index $\left(\mathrm{kg} / \mathrm{m}^{2}\right)$ & $21.7(20.8-24.4)$ & $20.7(20.1-24.5)$ & .47 \\
\hline Centre-edge angle $\left({ }^{\circ}\right)$ & $11.8(7.0-15.0)$ & $15.0(13.8-16.6)$ & .07 \\
\hline Hospitalization days (days) & $39.0(36.5-43.0)$ & $40.0(37.8-42.5)$ & .51 \\
\hline SLR possible (days) & $20.0(15.5-27.0)$ & $20.0(19.0-22.0)$ & .91 \\
\hline One-third partial weight bearing allowed (days) & $21.0(21.0-21.0)$ & $21.0(21.0-21.0)$ & .77 \\
\hline Full weight bearing allowed (weeks) & $13.4(11.0-14.9)$ & $14.6(13.9-17.1)$ & .02 \\
\hline \multicolumn{4}{|l|}{ Hip abductor muscle strength (\% body weight) } \\
\hline Operative side & $19.2(12.4-23.2)$ & $22.8(19.8-24.3)$ & .16 \\
\hline Non-operative side & $19.9(16.9-26.3)$ & $23.9(22.9-26.0)$ & .05 \\
\hline \multicolumn{4}{|l|}{ Knee extensor muscle strength (\% body weight) } \\
\hline Operative side & $38.6(26.2-49.2)$ & $42.2(36.5-51.4)$ & .60 \\
\hline Non-operative side & $41.6(25.5-51.2)$ & $48.2(44.2-51.7)$ & .16 \\
\hline \multicolumn{4}{|l|}{ Pain on operative side (VAS, mm) } \\
\hline Rest & $13.5(0.0-42.0)$ & $15.5(2.0-28.8)$ & .91 \\
\hline Gait & $48.5(25.5-80.3)$ & $48.5(30.5-53.5)$ & .93 \\
\hline \multicolumn{4}{|l|}{ Operative side range of motion $\left(^{\circ}\right)$} \\
\hline Hip extension & $12.0(5.0-15.5)$ & $15.0(11.3-18.8)$ & .21 \\
\hline Hip flexion & $110.0(93.8-115.5)$ & $117.5(115.0-120.0)$ & .03 \\
\hline Hip abduction & $30.0(24.8-35.0)$ & $30.0(26.3-33.8)$ & .83 \\
\hline Hip adduction & $14.5(10.0-15.0)$ & $15.0(10.0-18.8)$ & .77 \\
\hline Hip external rotation & $33.5(16.8-40.3)$ & $35.0(27.5-43.8)$ & .24 \\
\hline Hip internal rotation & $31.0(21.8-41.3)$ & $45.0(31.8-48.8)$ & .21 \\
\hline Comfortable gait speed (m/s) & $1.1(1.0-1.2)$ & $1.2(1.0-1.3)$ & .65 \\
\hline Maximum gait speed (m/s) & $1.7(1.5-1.8)$ & $1.6(1.5-1.7)$ & .84 \\
\hline Harris Hip Score (points) & $42.0(34.0-63.5)$ & $40.0(31.8-57.3)$ & .60 \\
\hline Post-operative time at questionnaire completion (months) & $30.0(18.0-48.0)$ & $43.0(22.3-45.8)$ & .71 \\
\hline \multicolumn{4}{|l|}{ JHEQ Score (points) } \\
\hline Total & $62.5(45.0-73.8)$ & $65.5(58.3-81.0)$ & .27 \\
\hline Pain & $22.0(22.0-26.0)$ & $25.5(23.5-27.3)$ & .08 \\
\hline Movement & $19.0(11.5-26.0)$ & $22.5(16.8-26.5)$ & .29 \\
\hline Mental & $21.0(14.0-25.0)$ & $20.0(16.0-28.0)$ & .73 \\
\hline Hip joint condition (VAS, mm) & $12.5(2.0-19.8)$ & $13.0(6.9-21.8)$ & .70 \\
\hline Forgotten Joint Score (points) & $60.4(50.5-75.0)$ & $74.0(68.8-79.2)$ & .08 \\
\hline
\end{tabular}

Values are expressed as median (1st-3rd quartile range). SLR Straight leg-raising exercise, VAS Visual analogue scale, JHEQ Japanese Orthopaedic Association HipDisease Evaluation Questionnaire

Table 2 Satisfaction with daily life and sports activities at the time of the questionnaire

\begin{tabular}{lll}
\hline & Daily life & Sports activities \\
\hline Very satisfied (\%) & 22.5 & 19.4 \\
Slightly satisfied (\%) & 51.6 & 19.4 \\
Neither (\%) & 9.7 & 38.7 \\
Slightly dissatisfied (\%) & 6.5 & 9.6 \\
Extremely dissatisfied (\%) & 9.7 & 12.9 \\
\hline
\end{tabular}

limited sports activities owing to living environmentrelated or psychological reasons.

In this study, patients who participated in sports activities had a smaller pre-operative hip flexion range of motion than those who did not participate in sports activities. Patients with acetabular dysplasia typically have increased hip flexion, which is reduced by $\mathrm{PAO}$ [22]. In other words, patients who participated in sports activities after CPO in this study likely had a smaller 
flexion angle compared to those who did not participate. Therefore, patients with acetabular dysplasia might be able to participate in post-operative sports activities if they have close-to-smaller hip flexion. In addition, FWB was allowed earlier among patients who participated in sports activities than those who did not, likely because early recovery of muscle strength is associated with early permission for FWB after osteotomy [23]. However, given that allowing FWB when bone fusion is insufficient increases the risk of fracture [24], safety must be prioritised over allowing FWB at an early stage regardless of individual characteristics.

One limitation of our study is its retrospective design using a self-reported questionnaire. Although recall bias might have influenced the results, the recall period was limited to 3 years pre-operatively to minimise such bias. Another limitation is lack of data, specifically postoperative physical function assessments. Although we examined pre-operative physical function and postoperative sports activity, if patients had a certain level of pre-operative physical function, pre-operative physical function might not significantly affect post-operative participation in sports activities. Therefore, further studies examining the effects of post-operative physical function and sports activity participation are needed. Another limitation is the small sample size: few patients were eligible for $\mathrm{CPO}$, especially considering the fiveyear study period. Therefore, multivariate analysis could not be performed.

\section{Conclusion}

Among acetabular dysplasia patients who underwent $\mathrm{CPO}, 72.1 \%$ participated in sports activities postoperatively, representing an increase compared to preoperative participation in sports activities. Furthermore, patients post-operatively participated not only in lowimpact sport activities, but also in high-impact sports activities. Patients who participated in sports activities post-operatively were allowed to return to FWB faster than those who did not. Therefore, these findings might be useful for advising patients who are concerned about participating in sports activities after CPO.

\section{Supplementary information}

Supplementary information accompanies this paper at https://doi.org/10. 1186/s12891-020-03625-3.

Additional file 1. Study questionnaire. Description of data: The questionnaire used for this study was developed specifically for this study. This questionnaire examined patients' participation in sports activities pre- and post-operatively, patients' current satisfaction with daily life and sports activities, and related patient-reported outcomes.

\section{Abbreviations}

BMI: Body mass index; CPO: Curved periacetabular osteotomy; FWB: Full weight bearing; HHS: Harris hip score; JHEQ: Japanese Orthopaedic
Association Hip-Disease Evaluation Questionnaire; OA: Osteoarthritis; PAO: Periacetabular osteotomy; SLR: Straight leg-raising exercise; VAS: Visual analogue scale

\section{Acknowledgments}

We thank the Kitasato University Hospital Department of Rehabilitation for supporting data collection.

\section{Authors' contributions}

NT contributed to the study conception. YT and NT contributed to the study design. NT, KF, KU and MM performed the curved periacetabular osteotomy. MT provided a research environment. YT, NT, KF, KU, MM, MS and MT contributed to the acquisition of data. Data analysis was mainly performed by YT, NT and KoTs. KoTs, KiTo, SK, HK and JS contributed to the interpretation of data and consideration of adequacy for data. YT and NT were major contributors in writing the manuscript and all authors contributed to drafting of the manuscript for important intellectual content. All authors read and approved the final version of the manuscript and have agreed to be personally accountable for their own contributions.

\section{Funding}

No external funding was received for this study.

\section{Availability of data and materials}

The datasets used and/or analysed during the current study are available from the corresponding author on reasonable request.

Ethics approval and consent to participate

The retrospective study was approved by Ethics Committee of Kitasato University Hospital (permit number: B18-064) and was performed in accordance with the Declaration of Helsinki. An opt-out form for informed consent was adopted.

\section{Consent for publication}

Not applicable.

\section{Competing interests}

The authors declare that they have no competing interests.

\section{Author details}

${ }^{1}$ Sensory and Motor Control, Graduate School of Medical Sciences, Kitasato University, 1-15-1 Kitasato, Minami-ku, Sagamihara-city, Kanagawa 252-0373, Japan. ${ }^{2}$ Department of Orthopaedic Surgery of Clinical Medicine,

Rehabilitation Sciences and Functional Restoration, Science of Sensory and Motor Control, Graduate School of Medical Sciences, Kitasato University, 1-15-1 Kitasato, Minami-ku, Sagamihara-city, Kanagawa 252-0373, Japan. ${ }^{3}$ Department of Rehabilitation, School of Allied Health Sciences, Kitasato University, 1-15-1 Kitasato, Minami-ku, Sagamihara-city, Kanagawa 252-0373, Japan. ${ }^{4}$ Department of Orthopaedic Surgery, School of Medicine, Kitasato University, 1-15-1 Kitasato, Minami-ku, Sagamihara-city, Kanagawa 252-0374 Japan. ${ }^{5}$ Department of Rehabilitation, Kitasato University Hospital, 1-15-1 Kitasato, Minami-ku, Sagamihara-city, Kanagawa 252-0375, Japan.

Received: 1 April 2020 Accepted: 1 September 2020

Published online: 28 September 2020

\section{References}

1. Jingushi S, Ohfuji S, Sofue M, Hirota $Y$, Itoman M, Matsumoto T, Hamada $Y$, Shindo H, Takatori Y, Yamada H, Yasunaga Y, Ito H, Mori S, Owan I, Fujii G, Ohashi H, Iwamoto $Y$, Miyanishi K, Iga T, Takahira N, Sugimori T, Sugiyama H, Okano K, Karita T, Ando K, Hamaki T, Hirayama T, Iwata K, Nakasone S, Matsuura M, Mawatari T. Multiinstitutional epidemiological study regarding osteoarthritis of the hip in Japan. J Orthop Sci. 2010;15(5):626-31.

2. Murphy SB, Kijewski PK, Millis MB, Harless A. Acetabular dysplasia in the adolescent and young adult. Clin Orthop Relat Res. 1990;261:214-23.

3. Maeyama A, Naito M, Moriyama S, Yoshimura I. Evaluation of dynamic instability of the dysplastic hip with use of triaxial accelerometry. J Bone Joint Surg Am. 2008;90(1):85-92.

4. lidaka T, Muraki S, Akune T, Oka H, Kodama R, Tanaka S, Kawaguchi $H_{1}$ Nakamura K, Yoshimura N. Prevalence of radiographic hip osteoarthritis and 
its association with hip pain in Japanese men and women: the ROAD study. Osteoarthr Cartil. 2016;24(1):117-23.

5. Novais EN, Heyworth B, Murray K, Johnson VM, Kim YJ, Millis MB. Physical activity level improves after periacetabular osteotomy for the treatment of symptomatic hip dysplasia. Clin Orthop Relat Res. 2013;471(3):981-8.

6. Bogunovic L, Hunt D, Prather H, Schoenecker PL, Clohisy JC. Activity tolerance after periacetabular osteotomy. Am J Sports Med. 2014;42(8):1791-5.

7. Steppacher SD, Tannast M, Ganz R, Siebenrock KA. Mean 20-year followup of Bernese periacetabular osteotomy. Clin Orthop Relat Res. 2008;466(7): 1633-44.

8. van Bergayk AB, Garbuz DS. Quality of life and sports-specific outcomes after Bernese periacetabular osteotomy. J Bone Joint Surg (Br). 2002;84(3): 339-43.

9. Hara D, Hamai S, Fukushi Jl, Kawaguchi KI, Motomura G, Ikemura S, Komiyama $\mathrm{K}$, Nakashima Y. Does participation in sports affect osteoarthritic progression after periacetabular osteotomy? Am J Sports Med. 2017;45(11):2468-75.

10. Naito M, Shiramizu K, Akiyoshi Y, Ezoe M, Nakamura Y. Curved periacetabular osteotomy for treatment of dysplastic hip. Clin Orthop Relat Res. 2005:433:129-35.

11. Karashima H, Naito M, Shiramizu K, Kiyama T, Maeyama A. A periacetabular osteotomy for the treatment of severe dysplastic hips. Clin Orthop Relat Res. 2011:469(5):1436-41.

12. Ezoe $M$, Naito $M$, Asayama I. Muscle strength improves after abductorsparing periacetabular osteotomy. Clin Orthop Relat Res. 2006;444:161-8.

13. Maeyama A, Naito M, Moriyama S, Yoshimura I. Periacetabular osteotomy reduces the dynamic instability of dysplastic hips. J Bone Joint Surg (Br). 2009;91(11):1438-42.

14. Kuroda D, Maeyama A, Naito M, Moriyama S, Yoshimura I, Nakamura Y, Kiyama T. Dynamic hip stability, strength and pain before and after hip abductor strengthening exercises for patients with dysplastic hips. Isokinet Exerc Sci. 2013;21(2):95-100.

15. Klein GR, Levine BR, Hozack WJ, Strauss EJ, D'Antonio JA, Macaulay W, Di Cesare PE. Return to athletic activity after total hip arthroplasty. Consensus guidelines based on a survey of the hip society and American Association of hip and Knee Surgeons. J Arthroplast. 2007;22(2):171-5.

16. Behrend $\mathrm{H}$, Giesinger $\mathrm{K}$, Giesinger JM, Kuster MS. The "forgotten joint" as the ultimate goal in joint arthroplasty: validation of a new patient-reported outcome measure. J Arthroplast. 2012;27(3):430-6.

17. Matsumoto $T$, Kaneuji A, Hiejima $Y$, Sugiyama $H$, Akiyama $H$, Atsumi $T$, Ishii M, Izumi K, Ichiseki T, Ito H, Okawa T, Ohzono K, Otsuka H, Kishida S, Kobayashi S, Sawaguchi T, Sugano N, Nakajima I, Nakamura S, Hasegawa Y, Fukuda K, Fujii G, Mawatari T, Mori S, Yasunaga Y, Yamaguchi M. Japanese Orthopaedic Association Hip Disease Evaluation Questionnaire (JHEQ): a patient-based evaluation tool for hip-joint disease. The Subcommittee on Hip Disease Evaluation of the Clinical Outcome Committee of the Japanese Orthopaedic Association. J Orthop Sci. 2012;17(1):25-38.

18. Harris WH. Traumatic arthritis of the hip after dislocation and acetabular fractures: treatment by mold arthroplasty. An end-result study using a new method of result evaluation. J Bone Joint Surg Am. 1969;51(4):737-55.

19. Ollivier $M$, Frey $S$, Parratte $S$, Flecher $X$, Argenson JN. Pre-operative function, motivation and duration of symptoms predict sporting participation after total hip replacement. Bone Joint J. 2014;96-B(8):1041-6.

20. Wylde V, Blom A, Dieppe P, Hewlett S, Learmonth I. Return to sport after joint replacement. J Bone Joint Surg (Br). 2008;90(7):920-3.

21. Huch K, Müller KA, Stürmer T, Brenner H, Puhl W, Günther KP. Sports activities 5 years after total knee or hip arthroplasty: the Ulm osteoarthritis study. Ann Rheum Dis. 2005;64(12):1715-20.

22. Steppacher SD, Zurmühle CA, Puls M, Siebenrock KA, Millis MB, Kim YJ, Tannast M. Periacetabular osteotomy restores the typically excessive range of motion in dysplastic hips with a spherical head. Clin Orthop Relat Res. 2015;473(4):1404-16

23. Ito H, Tanino H, Sato T, Nishida Y, Matsuno T. Early weight-bearing after periacetabular osteotomy leads to a high incidence of postoperative pelvic fractures. BMC Musculoskelet Disord. 2014;15:234.

24. Espinosa N, Strassberg J, Belzile EL, Millis MB, Kim YJ. Extraarticular fractures after periacetabular osteotomy. Clin Orthop Relat Res. 2008;466(7):1645-51.

\section{Publisher's Note}

Springer Nature remains neutral with regard to jurisdictional claims in published maps and institutional affiliations.

\section{Ready to submit your research? Choose BMC and benefit from:}

- fast, convenient online submission

- thorough peer review by experienced researchers in your field

- rapid publication on acceptance

- support for research data, including large and complex data types

- gold Open Access which fosters wider collaboration and increased citations

- maximum visibility for your research: over $100 \mathrm{M}$ website views per year

At BMC, research is always in progress.

Learn more biomedcentral.com/submissions 